\title{
Understanding the Thermal Annealing Behaviour of Metal Laser Sintered SUS316L Stainless Steel
}

\author{
J. J. H. Lim ${ }^{1}$, F. Harda ${ }^{1}$, L. R. C. Malheiros ${ }^{1}$ and M. G. Burke ${ }^{1}$ \\ ${ }^{1 .}$ Material Performance Centre, School of Materials, University of Manchester, Manchester (UK)
}

The high degree of design freedom and near-net-shape production capabilities of additive manufacturing (AM) technology are considered an important asset for the future manufacturing of structural components for advanced nuclear power systems. However, the manufacturing processinduced imperfections, such as residual stresses [1] and preferential grain growth orientation [2], could be life-time limiting factors for a structural component, particularly for those exposed to neutron irradiation.

In this investigation, the recyrstallisation behaviour during thermal annealing of a Metal Laser Sintered (MLS) SUS316L was studied. The as-deposited MLS SUS316L was previously characterised [3]. The MLS SUS316L material was annealed at $1100^{\circ} \mathrm{C}$ in an argon gas-filled environment for 120, 240 and 360 minutes. The microstructure of these annealed samples was characterized by using Electron Backscatter Diffraction (EBSD) and conventional transmission electron microscopy (TEM) techniques. TEM specimens of these samples were mechanically thinned and were electropolished using the Struers twin-jet Tenupol-5 system.

EBSD analyses revealed a strong texture with <101> parallel to the deposition/melting direction (Rolling Direction/Inverse Pole Figure-X direction; RD/IPF-X). This was observed for all thermal annealed samples. EBSD misorientation maps showed that 'residual strain' was still present in all thermal annealed samples, as shown in Figure 1. No obviously "recovered” or "recrystallized” grains were observed from the EBSD maps measured for all annealed samples. Surprisingly, TEM analyses of the annealed samples revealed no obvious decrease of number density of dislocations, as shown in Figure 2. Additional microstructural data will be discussed. Also, a possible mechanism to explain the inhibition of recovery and recrystallization will also be proposed and discussed.

\section{References:}

[1] Frazier, W. E. (2014). J. of Mat. Eng. \& Per. 23(6): 1917-1928

[2] Wu, A., et al. (2014). Met. \& Mat. Trans. A 45(13): 6260-6270

[3] J. J. H. Lim, L. R. C. Malheiros, G. Bertali, C. J. Long, P. D. Freyer and M. G. Burke (2015).

Microscopy and Microanalysis, (Suppl. 3), pp 467-468. Doi:10.1017/S143192761500313X. 

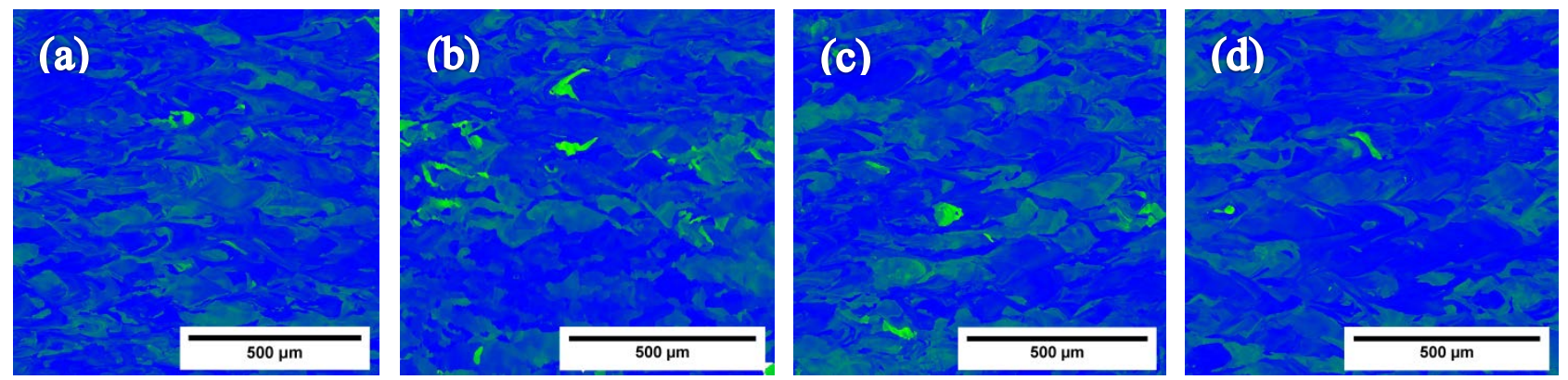

Figure 1. EBSD-Misorientation maps showing 'residual strain' (appeared as brighter contrast) detected in the MLS SUS316L. (a) as-manufactured and annealed at $1100^{\circ} \mathrm{C}$ for (b) 120 minutes, (c) 240 minutes \& (d) 360 minutes.

(a)

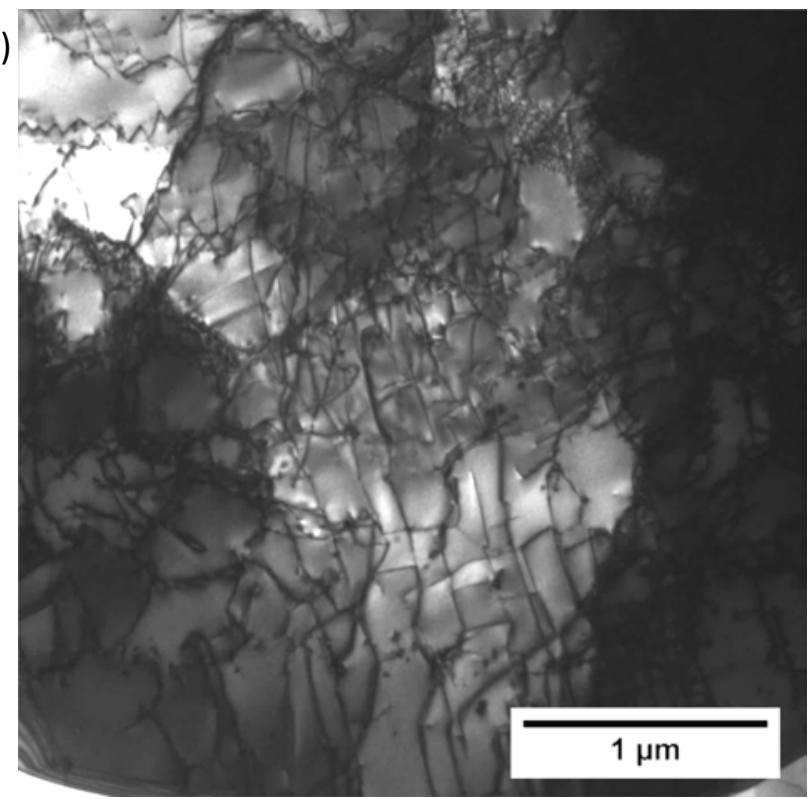

(c)

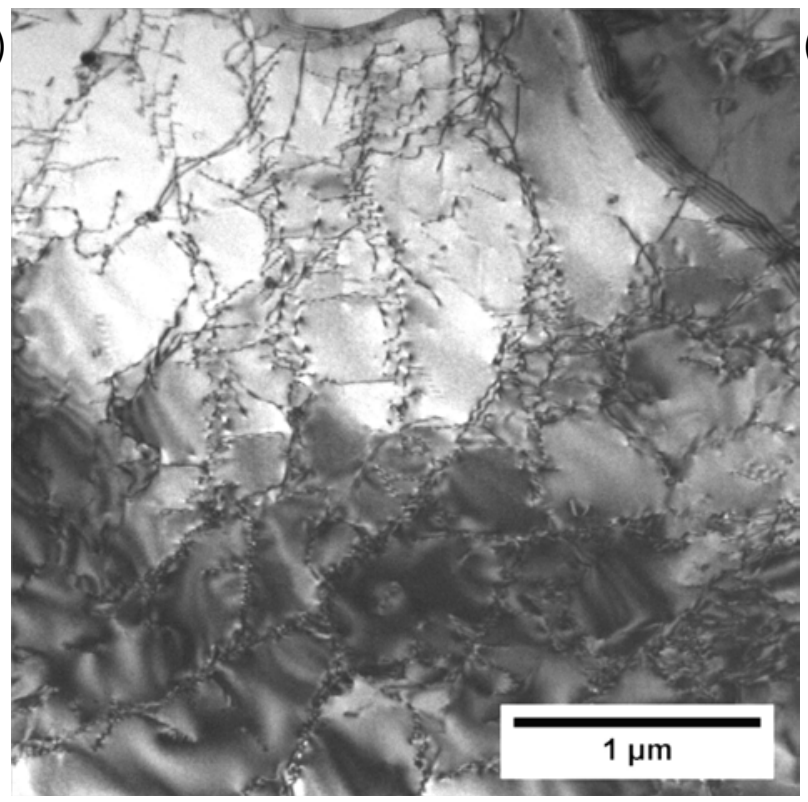

(b)

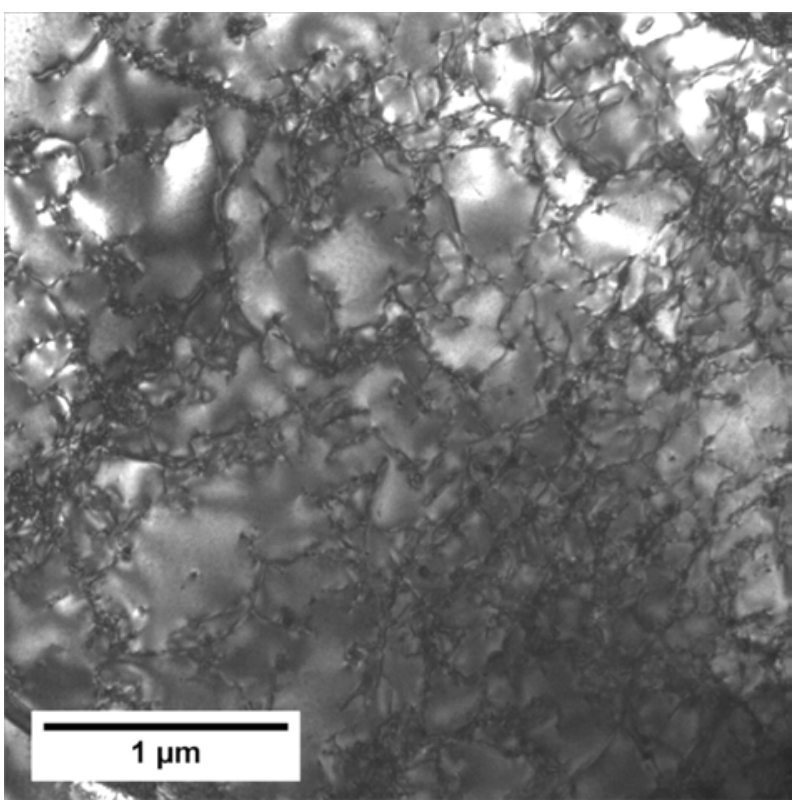

(d)

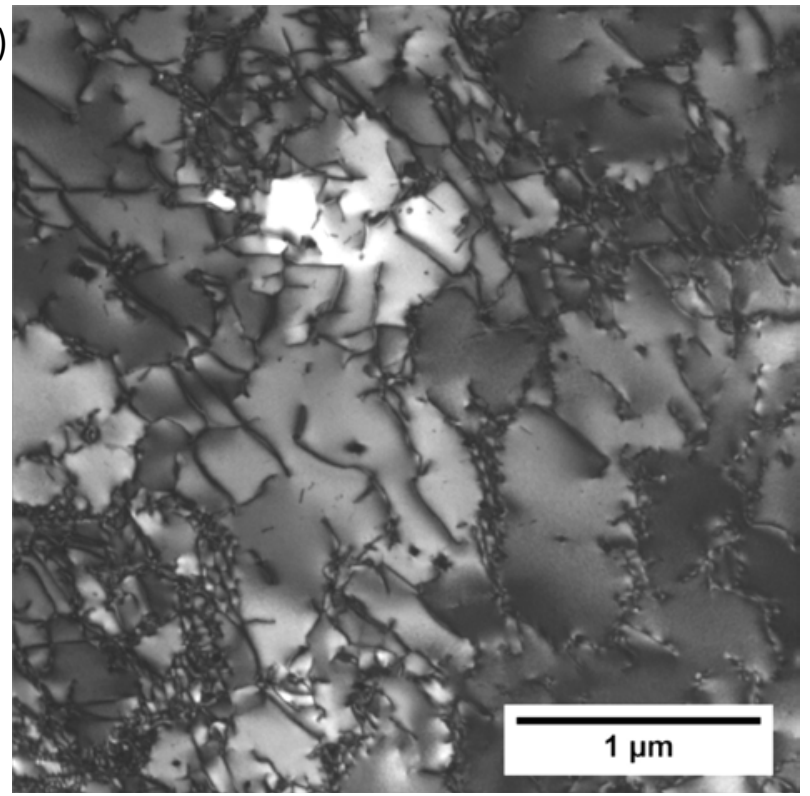

Figure 2. Bright-field (BF) TEM images showing dislocations networks of MLS SUS316L at zone axes $<111>$. (a) as-manufactured and annealed at $1100^{\circ} \mathrm{C}$ for (b) 120 minutes, (c) 240 minutes \& (d) 360 minutes. 